\title{
Outcomes of Sleep Disordered Breathing in Pregnancy
}

\author{
Ghada Bourjeily $^{1, *}$, Jeffrey Mazer ${ }^{2}$ and Michael J Paglia ${ }^{3}$ \\ ${ }^{I}$ Warren Alpert Medical School of Brown University, The Miriam Hospital, Department of Medicine, 146 West River St, \\ Providence, RI 02904, USA \\ ${ }^{2}$ Warren Alpert Medical School of Brown University, The Miriam Hospital, Department of Medicine, 164 Summit Street, \\ Providence, RI 02903, USA \\ ${ }^{3}$ Warren Alpert Medical School of Brown University, Geisinger Health System, Department of Obstetric and \\ Gynecology, 100 North Academy Avenue Danville PA 17822, USA
}

\begin{abstract}
Sleep disordered breathing has been linked to adverse cardiovascular outcomes in the general population. In pregnancy, sleep disordered breathing has also been linked to pathologic disorders that have been associated with long term cardiovascular and metabolic outcomes such as gestational hypertensive disorders and gestational diabetes mellitus. Endothelial dysfunction, sympathetic stimulation and inflammation are among the mechanisms proposed to explain the association with adverse outcomes. In addition to mechanistic research, future efforts need to focus on the effect of therapy on such outcomes.
\end{abstract}

Keywords: Pregnancy, snoring, sleep disordered breathing, preeclampsia, gestational diabetes, cesarean delivery, mechanisms.

\section{INTRODUCTION}

The course and outcomes of pregnancy are affected by many physiological changes and events. Pathological issues can also present or become clinically manifested during pregnancy. These changes can affect the health of both mother and fetus. The physiologic mechanisms of disease that are focused upon are primarily those that occur during waking hours.

Humans spend approximately one third of life asleep [1]. It is possible that pathologic changes occurring during sleep or resulting in poor sleep may also affect pregnancy outcomes. Like so many aspects of a woman's life, sleep is profoundly altered in many pregnant women by pregnancy physiology [2]. Sleep disruption starts in the first trimester and is related to factors such as nocturnal micturition and nocturnal heartburn. As pregnancy progresses, musculoskeletal discomfort related to ligamental relaxation, weight gain or leg cramps may disrupt sleep. Obstetric factors such as uterine contraction or fetal movement may also contribute to sleep fragmentation. Anatomical and physiological changes also occur in pregnancy leading to disturbed sleep, poor sleep quality and more frequent snoring as well as decreased daytime alertness [3]. Prevalence of self reported snoring is significantly higher in pregnancy affecting $14-45 \%$ of pregnant women in most studies [4-6] compared to $4 \%$ of the non-pregnant population. Excessive daytime sleepiness is also quite prevalent in the pregnant

*Address correspondence to this author at the Warren Alpert Medical School of Brown University, The Miriam Hospital, Department of Medicine, 146 West River St, Providence, RI 02904, USA;

Tel: (401) 793-7358; Fax: (401) 793-7801;

E-mail: ghada_bourjeily@brown.edu population [7] and appears to worsen with the course of pregnancy [8].

While many aspects of abnormal sleep may contribute to adverse outcomes, this manuscript will focus on pregnancy outcomes associated with sleep disordered breathing (SDB) while another review by Dr Tauman in this issue discusses fetal outcomes.

\section{PREGNANCY PHYSIOLOGY}

Cardiopulmonary physiology and sleep related physiologic changes have been reviewed in recently published manuscripts $[9,10]$. Briefly, pregnancy is associated with changes in upper airway size $[11,12]$ as well as mucosal edema and friability [13-16] which result in a decrease in airway patency and higher Mallampati grades [17]. Oxygen consumption increases by about $20 \%$ and functional residual capacity (FRC) decreases by about $20 \%$ near term with a more pronounced reduction in the supine position [18]. Cardiac output rises significantly in pregnancy but drops in the supine position in the latter half of pregnancy $[19,20]$. The reduced FRC and cardiac output may potentially affect supine oxygenation. Progesterone, a strong respiratory stimulant increases minute ventilation during the wake period [21] and estrogen decreases REM sleep [22-24]. These hormonal effects may theoretically have some protective effects against SDB.

\section{SDB AND ADVERSE CARDIOVASCULAR OUT- COMES}

SDB and its potential consequences such as sleep fragmentation, short sleep duration and desaturations have been associated with a variety of well characterized physiological responses such as sympathetic activation, 
endothelial dysfunction, systemic inflammation, and metabolic dysregulation [25] as well as a wide range of adverse outcomes. Of those many outcomes, cardiovascular disease is particularly relevant to pregnancy complications such as preeclampsia, gestational diabetes and intrauterine growth restriction. On the one hand these adverse outcomes share similar risk factors with cardiovascular disease; on the other, some of these outcomes have been associated with a higher risk of developing premature cardiovascular disease [26-28].

Links between SDB and adverse cardiovascular outcomes including hypertension $[29,30]$, congestive heart failure both systolic and diastolic [31], acute stroke, [32] arrhythmia and cardiac ischemia [33-36] have been evaluated. Although the physiologic link has been studied, establishing OSA as a direct causal event for these cardiovascular events has been more challenging [31, 37]. Moreover, many of the studies available lack the power to evaluate the effect of gender differences on such outcomes. The Sleep Heart Health study has shown a less robust effect of OSA on adverse cardiovascular outcomes in women [31]; such results are possibly related to a more delayed timing of these outcomes in women compared to men.

Several studies have also shown a relationship between diabetes and OSA. OSA was diagnosed in $86 \%$ of obese or overweight diabetic subjects in the Sleep AHEAD study [38, 39]. Despite a potential selection bias in this study, these findings remain quite remarkable. OSA has also been associated in many studies with measures of abnormal glucose metabolism and elevated glycosylated hemoglobin [40-43]. Snoring has also been associated with abnormal glucose tolerance [44] as well as a two-fold increased risk of developing type II diabetes mellitus over a period of ten years (RR 2.03, 1.17-2.40 95\% CI) [45]. Snoring was also shown to be an independent risk factor for type II diabetes in women in a large cross-sectional study [46].

\section{ADVERSE PREGNANCY OUTCOMES}

The majority of studies evaluating the association between SDB and adverse pregnancy outcomes have a cross sectional design [4-6, 47-50] and do not follow women longitudinally through pregnancy, precluding clear conclusions. Furthermore, the variables evaluated in these studies have differed, with some evaluating outcomes of snoring, others using questionnaires that have been validated in the non-pregnant population but not in pregnancy, while a small number of studies have evaluated outcomes of polysomnographically (PSG) diagnosed OSA. Physiologically, pregnancy can be thought of as a dynamic status that may affect the characterization of outcomes and exposures. Snoring in the first trimester likely suggests a condition predating pregnancy, whereas snoring that develops in the third trimester may be related to a pregnancy condition. The same is true for other conditions such as hypertension diagnosed in pregnancy. In addition, many of the outcomes that manifest clinically or are diagnosed in the third trimester such as preeclampsia, have their roots developing much earlier in pregnancy. For that reason, in order to evaluate causality of SDB, an exposure early in pregnancy would be ideal.

\section{GESTATIONAL HYPERTENSIVE DISORDERS}

Gestational hypertensive disorders include both transient gestational hypertension and preeclampsia. Gestational hypertension is defined as systolic blood pressure $\geq 140$ $\mathrm{mmHg}$ and/or diastolic blood pressure $\geq 90 \mathrm{mmHg}$ in a previously normotensive pregnant woman who is at $\geq 20$ weeks of gestation and has no proteinuria [51, 52]. If and when proteinuria develops $(>300 \mathrm{mg}$ proteins in a 24 hour urine collection or more than $2+$ on a urine dipstick), gestational hypertension is then termed preeclampsia. Gestational hypertension complicates about $6 \%$ of all pregnancies [53]. Chronic hypertension may also complicate a small percentage of pregnancies (3\%) [54] but elevated blood pressures are usually found before 20 weeks of gestation and persist beyond 12 weeks postpartum. Preeclampsia is a significant cause of maternal and fetal morbidity and mortality. It is associated with adverse maternal outcomes such as pulmonary edema, liver function abnormalities, renal failure and neurological complications, as well as adverse fetal outcomes including growth restriction, oligohydramnios and preterm birth.

In the past decade, numerous studies have evaluated the association between SDB and gestational hypertensive disorders [4-6, 47-50, 55-59]. The bulk of these studies evaluated snoring rather than polysomnographically diagnosed OSA [4-6, 47-50] and found a positive association with an adjusted odds ratio ranging from 1.82 (95\% CI 1.162.84) [49] to 2.9 (95\% CI 1.03-8.3) [5]. Most studies have adjusted for weight, weight gain and age [48, 49] while a few had a more extensive model that included diabetes, chronic hypertension, renal disease, multiple gestations and prior preeclampsia [4]. These findings suggest that snoring is possibly an independent predictor of gestational hypertensive disorders.

On the other hand, a study by Yin et al. evaluated a convenience selection of pregnant women oversampled for women with adverse pregnancy complications and recruited either during hospitalization or a routine prenatal visit [50]. This study used nocturnal oximetry as a surrogate for OSA and found no correlation between nocturnal desaturations and adverse pregnancy outcomes. Although the goal to achieve $80 \%$ power in this study was 100 normal pregnant women and 100 women with hypertension or growth restriction, the investigators were only able to recruit 78 normal pregnant women. Another study recruited pregnant women and non pregnant controls and screened them for snoring [47]. The study found a low incidence of habitual snoring $(2.5 \%)$ and a low incidence of preeclampsia (about $2 \%$ and no significant association between the two conditions. The lack of an association in the latter two studies is likely related to sample size and selection, with only a small percentage of subjects having the defined outcome and variable, and possibly because OSA was defined by the presence of oxygen desaturations and did not assess for flow limitations.

Some studies have considered positive screens for OSA as women who either screened high risk on the Berlin questionnaire [60] - or those with an Epworth Sleepiness Scale score (ESS) $>10$ [58]. ESS has not been shown to be a sensitive or specific measure of SDB in large cross sectional studies in the non-pregnant population [61]. This test is 
likely less specific in the pregnant population given the hormonal and inflammatory milieu of pregnancy and the physiologic sleep fragmentation. Berlin questionnaire has also been found to have a low sensitivity (35\%) and specificity (63.8\%) when 100 hospitalized pregnant women were screened for OSA between 26-39 weeks of gestation. Outcomes and associations in such studies are therefore harder to compare to others that have used mainly snoring or an actual diagnosis of OSA.

Fewer studies have evaluated PSG-diagnosed OSA and gestational hypertensive disorders. Louis et al. performed a retrospective case-control study comparing women diagnosed with OSA to a group of obese controls and a group of lean controls that do not carry the diagnosis [57]. The study has found a significant association with preeclampsia; however, one of the limitations acknowledged by the authors of the study is the fact that obese controls were not excluded for OSA, potentially affecting the association. A recent large population-based cohort study in Taiwan has examined the effects of PSG diagnosed OSA on adverse pregnancy and fetal outcomes [56]. This study identified 791 pregnant women with OSA and 3955 controls and compared the two groups for outcomes such as preeclampsia. The risk of preeclampsia and gestational hypertension in this study was found to be significantly elevated, even after adjusting for multiple confounders (adjusted OR 1.63, 1.07-2.48 and adjusted OR 3.18, 2.144.73, respectively). Interestingly, although the group with OSA had a significantly higher percentage of obese women than the control group $(2.1 \%$ vs. $1.5 \%, \mathrm{p}<0.001)$, the incidence of obesity is extremely low in the OSA group, suggesting a likely different mechanism for OSA in this population. Given that screening for OSA is quite low in many medical specialties and likely in obstetric specialties, the same limitation again applies to the group of controls that has not had the diagnosis of OSA excluded and has no data on screening for OSA documented.

A couple of case-control studies have evaluated the incidence of SDB in women with gestational hypertension, both with and without proteinuria $[55,59]$. The first study used two alternative definitions for hypopneas which consisted of either $50-90 \%$ decrease in airflow, or a $<50 \%$ reduction in airflow with a $4 \%$ desaturation or arousal (definition 1) or a stricter definition discounting events with $<50 \%$ reduction in airflow (definition 2 ). In this study, there was a significantly higher likelihood of OSA using either definition for AHI in the group with gestational hypertension compared to the group with normotensive pregnancies [55], but the AHI using definition 1 was higher than AHI using the more conservative definition $(38.6 \pm 36.7$ versus $21.6 \pm$ 35.2 respectively in the hypertensive group) [55]. In the second study, scoring was performed according to AASM criteria [62] and OSA defined as RDI $\geq 5$ [59]. This study also found a significantly higher incidence of OSA among the group with gestational hypertension compared to the normotensive group (53\% vs. 12\%) [59]. Interestingly, the hypertensive group was significantly more obese than the normotensive group (BMI 31.9 vs. 23.2, p<0.001) and had a larger neck circumference $(38.6 \mathrm{~cm}$ vs. $34.2 \mathrm{~cm}, \mathrm{p}<0.001)$. Earlier studies that had a more conservative definition for OSA (AHI >10) did not show evidence of the disorder in women with preeclampsia [63].
Briefly, based on mainly cross-sectional studies, SDB including snoring and OSA appear to be associated with gestational hypertensive disorders, even after adjusting for multiple confounders. With such designs, the directionality of the association cannot be ascertained and longitudinal and mechanistic studies can help further our understanding of the link between these two disorders. A recent study suggests that the association with hypertension is significant in women who started snoring in pregnancy, compared to those who snored prior to pregnancy [64]. These findings would need to be confirmed in longitudinal designs. Despite all these studies suggesting a significant association with adverse outcomes, providers for the pregnant population are not screening appropriately for sleep symptoms such as snoring and witnessed apneas [65].

\section{POTENTIAL MECHANISMS}

The underlying mechanism for the association of SDB with gestational hypertensive and other disorders has not been elucidated. Mechanistic pathways proposed in this manuscript are mostly hypothetical and remain to be tested.

Hypoperfusion, hypoxia and ischemia are important components in the pathogenesis of preeclampsia, because the ischemic placenta secretes a variety of soluble factors into the bloodstream that result in maternal endothelial dysfunction. Endothelial dysfunction is an early marker of vascular abnormalities that predates overt cardiovascular disease. Endothelial function can be assessed by various measures that detect its diverse functions of regulating vascular tone, maintaining a balanced pro-inflammatory / anti-inflammatory activity, coagulation homeostasis and endothelial repair function. Evidence suggests abnormal acetylcholine mediated vasorelaxation [66] and impaired flow-mediated vasodilation $[67,68]$ that persists three years after the diagnosis of preeclampsia [69]. Other evidence suggests decreased production of endothelial derived vasodilators, such as nitric oxide and prostacycline [70]. A study by Edwards et al. comparing pregnant women with preeclampsia and OSA to pregnant women with OSA but without preeclampsia showed that women with preeclampsia had higher blood pressure peaks following obstructive events than those without preeclampsia [71]. This study suggests that the augmented pressor response may be the result of endothelial dysfunction in preeclampsia.

Similar data are available in OSA where endotheliumdependent vasodilation has been shown to be reduced in non-pregnant patients with severe OSA compared to age and BMI matched controls [72, 73]. Reduced flow mediated dilation persisted after adjusting for co-morbidities in the Sleep Heart Health Study [74]. Other measures of reduced endothelial function have been found in OSA such as reduced levels of nitric oxide in the endothelial cells and the plasma, [75, 76] increased levels of endogenous NO synthase inhibitor, [77] and increased levels of circulating soluble adhesion molecules that mediate leukocyte adhesion to the vascular endothelium [78] as well as other measures of impaired vascular pro-inflammatory / anti-inflammatory homeostasis [79].

There is a paucity of data assessing endothelial dysfunction as a potential mechanism for the association in pregnancy. One study has assessed sleep using a device that 
combines measurements of pulse, actigraphy, oxygen saturation and arterial vascular tone and measured endothelial function using non-invasive beat to beat plethysmography to measure arterial pulse wave amplitude [80]. The study showed a significant association between preeclampsia, OSA, and endothelial dysfunction in pregnant women [80]. Both intermittent hypoxia / reoxygenation [81, 82] and sleep fragmentation / deprivation secondary to repetitive arousals in OSA $[83,84]$ may lead to endothelial dysfunction.

In pregnancy, data from chronically hypoxic highaltitude residents suggest higher rates of preeclampsia and fetal growth restriction compared with low-altitude residents $[85,86]$. There are limited data on the direct effect of intermittent hypoxia on pregnancy outcomes. Theoretically, given that endothelial dysfunction may be the common pathway between OSA and preeclampsia, intermittent hypoxia caused by OSA may potentially be the driving force causing endothelial dysfunction. However, a small number of PSG data in pregnant women diagnosed with OSA suggests that these women are diagnosed mainly on the basis of flow limitation and arousals rather than desaturations. A study that evaluated the incidence of OSA in women diagnosed with gestational hypertensive disorders has shown a significantly higher number of events when $4 \%$ desaturation was eliminated as a requirement for the definition of hypopnea [55]. Another more recent study with a similar design showed a mean AHI of only $3.1 \pm 6.2$ in the group of women diagnosed with OSA based on RDI with mean of $11.5 \pm 11.2$ [59].

Other studies have found air flow limitations during sleep - without overt apneas - in women with either preeclampsia or risk factors for preeclampsia. A study by Connolly et al. measured an index of inspiratory flow limitation referred to as the flattening index in women with preeclampsia compared to a normotensive pregnant and a non-pregnant group [87]. The flattening index gives a measure of inspiratory flow limitation that is derived from the relationship of inspiratory flow to inspiratory duration. The study showed that despite a similar number of apneas and hypopneas in the case and the control groups, frequent, prolonged air flow limitations without significant desaturations were identified in patients with preeclampsia compared with normal pregnant and nonpregnant women. Edwards et al. have shown similar findings while using either visual measures of airflow limitations or following measurements of the area under the curve for tidal breaths of randomly selected epochs in each sleep stage [63]. Air flow limitations were also present in a noncontrolled study of patients with risk factors for preeclampsia [88]. In this study airflow limitation was defined as a reduction of $2-30 \%$ in the nasal cannula signal compared to baseline normal breathing [88]. As highlighted in these studies, airflow limitations appear to be present in women with preeclampsia or with risk factors for the disorder; however, these airflow limitations have been measured and defined very differently in the above studies.

On the other hand, treatment of patients with risk factors for preeclampsia and air flow limitations (but not SDB) with continuous positive airway pressure (CPAP) has shown beneficial blood pressure effects $[88,89]$ and improved fetal outcomes when compared with controls [89]. These findings indirectly suggest that even in the absence of hypoxia and reoxygenation, air flow limitation may have a role in causing hemodynamic changes in patients at risk for preeclampsia who do not have apneas or hypopneas. However, given the very small sample size in these studies, larger trials are needed to help answer this question.

Sympathetic stimulation and oxidative stress enhanced by hypoxia, flow limitation and sleep fragmentation are other potential mechanisms for the association of SDB and gestational hypertensive disorders. Sympathetic activation has been well established in OSA [90]. Higher levels of catecholamines are associated with higher blood pressure readings potentially contributing to, or worsening preeclampsia. Increased oxidative stress has also been demonstrated in OSA in non-pregnant patients [91, 92]. Very limited data examining the presence of oxidative stress in relation to SDB are available in pregnancy. One study has found that pregnant snorers had higher levels of oxidative stress markers such as malondialdehyde compared with nonsnoring pregnant controls [93].

Inflammation is possibly another pathway for the association. Both short sleep duration and poor sleep have been associated with elevated levels of interleukin-6 in mid to late pregnancy $[94,95]$ and tumor necrosis factor alpha in late gestation [94]. The same inflammatory markers have been suggested in preeclampsia [96].

Angiotensin converting enzyme (ACE) insertion / deletion (I/D) gene polymorphism has been studied as a possible common pathway for obstructive sleep apnea and chronic hypertension. Some studies have shown that the ACE D allele has either a protective effect against the development of hypertension in patients with OSA [97] or evidence of reciprocal interactions [98]. However, results are quite conflicting and a recent meta-analysis has shown a large male predominance in both cases and controls and no significant association [99]. The association of ACE I/D gene polymorphism with preeclampsia has also been evaluated; however, results are also conflicting with two meta-analyses, published a month apart, showing a possible significant association in one [100] but not the other [101].

The placenta plays a central role in the development of preeclampsia as evidenced by epidemiologic and experimental data. These data suggest that the presence of a placenta - but not a fetus - is necessary for the development of preeclampsia, and that delivery of the placenta results in a cure. Maternal spiral arteries - small branches of the uterine artery - undergo remodeling early in gestation and are transformed from small muscular arteries into large capacitance arteries of low resistance capable of facilitating blood flow into the placenta in normal pregnancies. In preeclampsia, this phenomenon is defective and the abnormal placentation and resulting ischemia are thought to be the primary event leading to the release of soluble factors that cause the systemic reaction, triggering the clinical manifestations of preeclampsia. Despite this and the association of preeclampsia with SDB, the placenta has not been studied in this setting. We described a small case series of pregnant patients with OSA diagnosed following various clinical scenarios that had placental pathological changes similar to those seen in gestational diabetes or preeclampsia, 
even in the absence of a clinical diagnosis of these disorders [102]. It is possible that such changes may be related to confounders such as obesity; however, the effects of obesity on the placenta are not known either. Further studies of the effect of SDB on the placenta are needed.

Another direction of the association is also possible where preeclampsia, based on mechanical factors and fluid shifts, may predispose to the de novo development of OSA. Patients with preeclampsia have lower oncotic pressures than normal pregnant women; they also have a larger neck circumference and a smaller upper airway size [11]; these factors are known predictors of SDB. Longitudinal studies evaluating the incident development of one disorder in the presence of the other would help answer this question.

\section{GESTATIONAL DIABETES}

Gestational diabetes is defined as any degree of glucose intolerance with onset or first recognition during pregnancy. Reported rates of gestational diabetes range from 2 to 10 percent of pregnancies [103] but may be significantly higher depending on the definition used [104]. Gestational diabetes is associated with many pregnancy complications, including macrosomia, cesarean delivery, birth trauma, preterm delivery, preeclampsia and intrauterine fetal demise.

A growing body of evidence suggests an association of short sleep duration, snoring, OSA and gestational diabetes. In a cross sectional study performed at a tertiary care, university hospital on 1000 patients recruited in the immediate postpartum period, we demonstrated a significant association between gestational diabetes and third trimester snoring (aOR 2.1, 1.3-3.4, 95\% CI) [4]. The association was much stronger when all three symptoms of snoring, gasping and witnessed apneas were present, and persisted after adjusting for age, BMI at delivery and multiple gestations (aOR 4.0, 1.4-11.1, 95\% CI). Another cohort study by Qiu et al. [105] has evaluated snoring in early pregnancy. Although the study showed an elevated relative risk for gestational diabetes in overweight women who do not snore (aRR 2.85, $1.65-4.0195 \% \mathrm{CI}$ ), the risk was much higher in overweight women who did snore (aRR 6.91, 2.87-16.6, 95\% CI). Smaller studies showed that frequent snorers had higher glucose tolerance values [106] and a higher likelihood of gestational diabetes [107].

The risk of GDM was also found to be higher in women with self-reported short sleep duration [105-107]. In the study by Facco et al., pregnant women with self reported short sleep duration defined as less than 7 hours of sleep was found to be at a significantly higher risk of having a 1h GTT $>130$ and a diagnosis of GDM compared to women without short sleep duration [106]. In addition, mean 1-hour plasma glucose concentrations was highest for women who reported short habitual sleep duration and lowest in those who reported sleeping an average of 9 hours per night [105].

A significant association was also found between polysomnographically diagnosed OSA and gestational diabetes in a cohort study in Taiwan, even after adjusting for confounders including gestational hypertension, obesity, parity and others (1.63, 1.07-2.48 CI 95\%) [56]. A noteworthy fact in this study was the fact that although obesity was more common in the OSA group compared to controls, it was only found in $2.1 \%$ of cases and $1.5 \%$ of controls. This is a significant finding suggesting that the association may be independent of body habitus, a significant confounder in the western world.

\section{POTENTIAL MECHANISMS}

The etiology of abnormal glucose metabolism in relation to SDB may be related to sympathetic activation, dysregulation of the hypothalamic-pituitary-adrenal (HPA) axis, intermittent hypoxia and oxidative stress, as well as inflammation. Increased sympathetic activation can be caused by airflow limitation, sleep fragmentation or intermittent hypoxia and can inhibit pancreatic insulin secretion, worsen insulin resistance, decrease glucose effectiveness and stimulate hepatic glucose release [108111]. Dysregulation of the HPA axis and glucocorticoid secretion worsen insulin resistance and inhibit insulin secretion by modifying the insulin mediated glucose transport system [112].

Oxidative stress and reactive oxygen species result in pancreatic beta cell damage [113] resulting in a reduction in insulin secretion. Inflammation may be a potential mechanism linking gestational diabetes and SDB, with interleukin-6 and TNF- $\alpha$ being potential culprits [114-121]. Oxidative stress, IL- 6 and TNF- $\alpha$ all reduce levels of adiponectin, a hormone with anti-atherogenic and antiinflammatory properties. Adiponectin levels were also found to have a protective effect against endothelial injury [120]. Levels of this polypeptide are reduced in diabetes and OSA, with recent studies showing a significant reduction in women with gestational diabetes [120].

\section{PRETERM LABOR}

Infants are born preterm at less than 37 weeks of gestation after either preterm premature rupture of the membranes, spontaneous labor with intact membranes, or labor induction or cesarean delivery for maternal or fetal indications. Preterm birth is a significant source of morbidity and mortality in newborns and accounts for $75 \%$ of neonatal mortality and more than half the long term morbidity [122]. Preterm labor is thought to be initiated by one or more of multiple mechanisms including infection or inflammation, uteroplacental ischemia or hemorrhage, overdistention of the uterus, or immunologically mediated processes. Although multiple obstetric and non-obstetric risk factors for preterm labor have been identified, obesity, an important risk factor for sleep disordered breathing, may play a protective role against spontaneous preterm labor [123]. On the other hand, obese women are more likely to develop preeclampsia or gestational diabetes, or have infants with congenital abnormalities and have more indicated preterm deliveries. However, according to a preterm prediction study evaluating BMI and the risk of preterm labor, women with a BMI of 3034.9 had a $7.1 \%$ risk of spontaneous preterm birth and $5.8 \%$ risk of indicated preterm birth compared to $11.3 \%$ and $3.7 \%$ respectively in women with a BMI of 19-24.9 [124].

Few studies have evaluated the association between preterm labor or preterm birth and SDB. Snoring [4] and OSA [57] have both been associated with preterm birth in cohort and case control studies. In a cross sectional study, [4] women with fetal or neonatal demise were excluded for 
compassionate reasons, possibly affecting the association. Based on the recruited sample, the association with preterm labor ceased to be statistically significant when the model was adjusted for preeclampsia occurring in the index pregnancy. Thus, preterm labor is likely mediated by the association with preeclampsia [4]. In the case control study, it appeared that indicated - but not spontaneous - preterm birth was significantly associated with OSA, with early delivery for preeclampsia being the most common cause for prematurity [57]. A recent population- based study showed a significant association between preterm births and OSA but did not adjust for preeclampsia in the regression model [56].

Another cohort study with low incidence of snoring (4\% of all pregnant women) showed no significant association between snoring and preterm birth [125]. However, the association between reported short sleep duration ( $\leq 5$ hours) and indicated that preterm delivery was significant, even after adjusting for age, pre-pregnancy BMI, maternal education and smoking.

Based on the current studies, it appears that OSA and snoring are not independent predictors of preterm birth and the association is more than likely related to confounders.

\section{CESAREAN DELIVERIES}

Maternal morbidities such as obesity that are often associated with cesarean delivery are also associated with OSA. Two recent studies have shown a relationship between OSA and cesarean delivery $[56,57]$. In a univariate analysis of women diagnosed with OSA by PSG, those with OSA were at a significantly higher risk of cesarean delivery when compared to obese and normal weight women. OSA was also associated with wound complications which may be secondary to poor tissue perfusion. In multivariate analysis OSA was associated with composite maternal morbidity [57]. In a large retrospective cohort of Asian women, 50\% of those with OSA diagnosed by PSG underwent a cesarean delivery compared to $37 \%$ without OSA. This difference in cesarean section rate between women with OSA and those without remained significant when a multivariate analysis was performed [56]. In a study evaluating the effect of snoring on mode of delivery self-reported snoring and gasping were associated with an increase in the number of unplanned, but not planned- cesarean section [4]. The study did not, however, examine whether unplanned cesarean deliveries were related to obstetric causes such as poor progression of labor, pelvic outlet dimensions or due to fetal compromise. Short sleep duration, defined as $<6$ hours of sleep on actigraphy, was shown to increase the risk of having an unplanned cesarean delivery in 132 primiparous women [126]. These findings were contradictory to prior studies which have concluded that short self-reported sleep duration does not impact labor and delivery [127].

These data suggest that women with snoring, short sleep duration or OSA may be at a higher risk of cesarean delivery and postoperative complications. Future studies are needed to evaluate the exact causes requiring Cesarean delivery to help clarify the role that snoring, OSA, sleep duration or sleep fragmentation play in this observation.

\section{SUMMARY}

SDB is associated with adverse pregnancy outcomes such as gestational hypertensive disorders and gestational diabetes mellitus. Although causality and mechanisms of such associations have not been clearly established, epidemiologic cohort studies and case control studies seem to support the association. Many mechanistic pathways are plausible in the association such as arousals, sleep fragmentation, flow limitations and intermittent hypoxia. The link between SDB and preterm birth is likely related to confounders such as preeclampsia. Finally, despite limited data, an association between SDB and cesarean delivery seems to exist but needs to be studied further.

\section{CONFLICT OF INTEREST}

The authors confirm that this article content has no conflicts of interest.

\section{ACKNOWLEDGEMENTS}

The authors thank Beth Hott for her assistance in manuscript preparation.

\section{REFERENCES}

[1] Saper CB, Cano G, Scammell TE. Homeostatic, circadian, and emotional regulation of sleep. J Comp Neurol 2005; 493: 92-8.

[2] Bourjeily G, Mohsenin V. Sleep physiology in pregnancy. In: Rosene-Montella K, Bourjeily G, Eds. Pulmonary Problems in Pregnancy. New York: Humana Press 2009; pp. 37-55.

[3] Izci B, Martin SE, Dundas KC, Liston WA, Calder AA, Douglas NJ. Sleep complaints: snoring and daytime sleepiness in pregnant and pre-eclamptic women. Sleep Med 2005; 6: 163-9.

[4] Bourjeily G, Raker CA, Chalhoub M, Miller MA. Pregnancy and fetal outcomes of symptoms of sleep-disordered breathing. Eur Respir J 2010; 36: 849-55.

[5] Calaora-Tournadre D, Ragot S, Meurice JC, et al. Obstructive Sleep apnea syndrom during pregnancy: prevalence of main symptoms and relationship with pregnancy induced-hypertension and intra-uterine growth retardation. Rev Med Interne 2006; 27 : 291-5.

[6] Ursavas A, Karadag M, Nalci N, Ercan I, Gozu RO. Self-reported snoring, maternal obesity and neck circumference as risk factors for pregnancy-induced hypertension and preeclampsia. Respiration 2008; 76: 33-9.

[7] Bourjeily G, Raker C, Chalhoub M, Miller M. Excessive daytime sleepiness in late pregnancy may not always be normal: Results from a cross sectional study. Sleep Breath 2012; 17(2): 735-40.

[8] Pien GW, Fife D, Pack AI, Nkwuo JE, Schwab RJ. Changes in symptoms of sleep-disordered breathing during pregnancy. Sleep 2005; 28: 1299-305.

[9] Bourjeily G, Ankner G, Mohsenin V. Sleep-disordered breathing in pregnancy. Clin Chest Med 2011; 32: 175-89.

[10] Hegewald MJ, Crapo RO. Respiratory physiology in pregnancy. Clin Chest Med 2011; 32: 1-13.

[11] Izci B, Vennelle M, Liston WA, Dundas KC, Calder AA, Douglas NJ. Sleep-disordered breathing and upper airway size in pregnancy and post-partum. Eur Respir J 2006; 27: 321-7.

[12] Izci B, Riha RL, Martin SE, et al. The upper airway in pregnancy and pre-eclampsia. Am J Respir Crit Care Med 2003; 167: 137-40.

[13] Camann WR, Ostheimer GW. Physiological adaptations during pregnancy. Int Anesthesiol Clin 1990; 28: 2-10.

[14] Elkus R, Popovich J, Jr. Respiratory physiology in pregnancy. Clin Chest Med 1992; 13: 555-65.

[15] Mabry RL. Rhinitis of pregnancy. South Med J 1986; 79: 965-71.

[16] Schatz M, Zeiger RS. Diagnosis and management of rhinitis during pregnancy. Allergy Proc 1988; 9: 545-54.

[17] Pilkington S, Carli F, Dakin MJ, et al. Increase in Mallampati score during pregnancy. Br J Anaesth 1995; 74: 638-42. 
[18] Cugell DW, Frank NR, Gaensler EA, Badger TL. Pulmonary function in pregnancy. I. Serial observations in normal women. Am Rev Tuberc 1953; 67: 568-97.

[19] Kinsella SM, Lee A, Spencer JA. Maternal and fetal effects of the supine and pelvic tilt positions in late pregnancy. Eur J Obstet Gynecol Reprod Biol 1990; 36: 11-7.

[20] Mendonca C, Griffiths J, Ateleanu B, Collis RE. Hypotension following combined spinal-epidural anaesthesia for Caesarean section. Left lateral position vs. tilted supine position. Anaesthesia 2003; 58: 428-31.

[21] Contreras G, Gutierrez M, Beroiza T, et al. Ventilatory drive and respiratory muscle function in pregnancy. Am Rev Respir Dis 1991; 144: 837-41.

[22] Branchey M, Branchey L, Nadler RD. Effects of estrogen and progesterone on sleep patterns of female rats. Physiol Behav 1971; 6: 743-6.

[23] Colvin GB, Whitmoyer DI, Lisk RD, Walter DO, Sawyer CH. Changes in sleep-wakefulness in female rats during circadian and estrous cycles. Brain Res 1968; 7: 173-81.

[24] Fang J, Fishbein W. Sex differences in paradoxical sleep: influences of estrus cycle and ovariectomy. Brain Res 1996; 734: 275-85.

[25] Shamsuzzaman AS, Gersh BJ, Somers VK. Obstructive sleep apnea: implications for cardiac and vascular disease. JAMA 2003; 290: 1906-14.

[26] Agatisa PK, Ness RB, Roberts JM, Costantino JP, Kuller LH, McLaughlin MK. Impairment of endothelial function in women with a history of preeclampsia: an indicator of cardiovascular risk. Am J Physiol Heart Circ Physiol 2004; 286: H1389-93.

[27] Ray JG, Vermeulen MJ, Schull MJ, Redelmeier DA. Cardiovascular health after maternal placental syndromes (CHAMPS): population-based retrospective cohort study. Lancet 2005; 366: 1797-803.

[28] Smith GN, Walker MC, Liu A, et al. A history of preeclampsia identifies women who have underlying cardiovascular risk factors. Am J Obstet Gynecol 2009; 200: 58 e1-8

[29] Nieto FJ, Young TB, Lind BK, et al. Association of sleepdisordered breathing, sleep apnea, and hypertension in a large community-based study. Sleep Heart Health Study. JAMA 2000; 283: $1829-36$

[30] Peppard PE, Young T, Palta M, Skatrud J. Prospective study of the association between sleep-disordered breathing and hypertension. N Engl J Med 2000; 342: 1378-84.

[31] Gottlieb DJ, Yenokyan G, Newman AB, et al. Prospective study of obstructive sleep apnea and incident coronary heart disease and heart failure: the sleep heart health study. Circulation 2010;122: 352-60.

[32] Redline S, Yenokyan G, Gottlieb DJ, et al. Obstructive sleep apnea-hypopnea and incident stroke: the sleep heart health study. Am J Respir Crit Care Med 2010; 182: 269-77.

[33] Marin JM, Carrizo SJ, Vicente E, Agusti AG. Long-term cardiovascular outcomes in men with obstructive sleep apnoeahypopnoea with or without treatment with continuous positive airway pressure: an observational study. Lancet 2005; 365: 104653.

[34] Mooe T, Rabben T, Wiklund U, Franklin KA, Eriksson P. Sleepdisordered breathing in men with coronary artery disease. Chest 1996; 109: 659-63.

[35] Peker Y, Kraiczi H, Hedner J, Loth S, Johansson A, Bende M. An independent association between obstructive sleep apnoea and coronary artery disease. Eur Respir J 1999; 14: 179-84.

[36] Saito T, Yoshikawa T, Sakamoto Y, Tanaka K, Inoue T, Ogawa R. Sleep apnea in patients with acute myocardial infarction. Crit Care Med 1991; 19: 938-41.

[37] O'Connor GT, Caffo B, Newman AB, et al. Prospective study of sleep-disordered breathing and hypertension: the Sleep Heart Health Study. Am J Respir Crit Care Med 2009; 179: 1159-64.

[38] Foster G, Borradaile K, Sanders M, et al. A randomized study on the effect of weight loss on obstructive sleep apnea among obese patients with type 2 diabetes: the Sleep AHEAD study. Arch Intern Med 2009; 169: 1619-26.

[39] Foster GD, Sanders MH, Millman R, et al. Obstructive sleep apnea among obese patients with type 2 diabetes. Diabetes Care 2009; 32: 1017-9.
[40] Joo S, Lee S, Choi HA, et al. Habitual snoring is associated with elevated hemoglobin A1c levels in non-obese middle-aged adults. J Sleep Res 2006; 15: 437-44.

[41] Otake K, Sasanabe R, Hasegawa R, et al. Glucose intolerance in Japanese patients with obstructive sleep apnea. Intern Med 2009; 48: 1863-8

[42] Punjabi NM, Beamer BA. Alterations in Glucose Disposal in Sleep-disordered Breathing. Am J Respir Crit Care Med 2009; 179 : 235-40.

[43] Theorell-Haglow J, Berne C, Janson C, Lindberg E. Obstructive sleep apnoea is associated with decreased insulin sensitivity in females. Eur Respir J 2008; 31: 1054-60.

[44] Jennum P, Sjol A. Snoring, sleep apnoea and cardiovascular risk factors: the MONICA II Study. Int J Epidemiol 1993; 22: 439-44.

[45] Al-Delaimy WK, Manson JE, Willett WC, Stampfer MJ, Hu FB. Snoring as a risk factor for type II diabetes mellitus: a prospective study. Am J Epidemiol 2002; 155: 387-93.

[46] Lindberg E, Berne C, Franklin KA, Svensson M, Janson C. Snoring and daytime sleepiness as risk factors for hypertension and diabetes in women--a population-based study. Respir Med 2007; 101: 128390

[47] Ayrim A, Keskin EA, Ozol D, Onaran Y, Yiidirim Z, Kafali H. Influence of self-reported snoring and witnessed sleep apnea on gestational hypertension and fetal outcome in pregnancy. Arch Gynecol Obstet 2011; 283: 195-9.

[48] Franklin KA, Holmgren PA, Jonsson F, Poromaa N, Stenlund H, Svanborg E. Snoring, pregnancy-induced hypertension, and growth retardation of the fetus. Chest 2000; 117: 137-41.

[49] Perez-Chada D, Videla AJ, O'Flaherty ME, et al. Snoring, witnessed sleep apnoeas and pregnancy-induced hypertension. Acta Obstet Gynecol Scand 2007; 86: 788-92

[50] Yin TT, Williams N, Burton C, et al. Hypertension, fetal growth restriction and obstructive sleep apnoea in pregnancy. Eur J Obstet Gynecol Reprod Biol 2008; 141: 35-8.

[51] American Sleep Disorders Associations. The international classification of sleep disorders, Revised : Diagnostic and coding manual. Rochester, MN: American Academy of Sleep Medicine 2000 .

[52] Sibai BM. Diagnosis and management of gestational hypertension and preeclampsia. Obstet Gynecol 2003; 102: 181-92.

[53] Yoder SR, Thornburg LL, Bisognano JD. Hypertension in pregnancy and women of childbearing age. Am J Med 2009; 122 : 890-5.

[54] Lain KY, Roberts JM. Contemporary concepts of the pathogenesis and management of preeclampsia. JAMA 2002; 287: 3183-6.

[55] Champagne K, Schwartzman K, Opatrny L, et al. Obstructive sleep apnoea and its association with gestational hypertension. Eur Respir J 2009; 33: 559-65.

[56] Chen YH, Kang JH, Lin CC, Wang IT, Keller JJ, Lin HC Obstructive sleep apnea and the risk of adverse pregnancy outcomes. Am J Obstet Gynecol 2012; 206: 136 e1-5.

[57] Louis JM, Auckley D, Sokol RJ, Mercer BM. Maternal and neonatal morbidities associated with obstructive sleep apnea complicating pregnancy. Am J Obstet Gynecol 2010; 202: 261 e15.

[58] Olivarez SA, Ferres M, Antony K, et al. Obstructive Sleep Apnea Screening in Pregnancy, Perinatal Outcomes, and Impact of Maternal Obesity. Am J Perinatol 2011; 28: 651-8.

[59] Reid J, Skomro R, Cotton D, et al. Pregnant women with gestational hypertension may have a high frequency of sleep disordered breathing. Sleep 2011; 34: 1033-8.

[60] Olivarez SA, Maheshwari B, McCarthy M, et al. Prospective trial on obstructive sleep apnea in pregnancy and fetal heart rate monitoring. Am J Obstet Gynecol 2010; 202: 552.e1-7.

[61] Kapur VK, Baldwin CM, Resnick HE, Gottlieb DJ, Nieto FJ Sleepiness in patients with moderate to severe sleep-disordered breathing. Sleep 2005; 28: 472-7.

[62] Silber $\mathrm{MH}$, Ancoli-Israel S, Bonnet $\mathrm{MH}$, et al. The visual scoring of sleep in adults. J Clin Sleep Med 2007; 3: 121-31.

[63] Edwards N, Blyton DM, Kirjavainen T, Kesby GJ, Sullivan CE Nasal continuous positive airway pressure reduces sleep-induced blood pressure increments in preeclampsia. Am J Respir Crit Care Med 2000; 162: 252-7.

[64] O'Brien LM, Bullough AS, Owusu JT, et al. Pregnancy-onse habitual snoring, gestational hypertension, and preeclampsia: prospective cohort study. Am J Obstet Gynecol 2012; 207(6): 487. 
[65] Bourjeily G, Raker C, Paglia MJ, Ankner G, O'Connor K. Patient and provider perceptions of sleep disordered breathing assessment during prenatal care: a survey-based observational study. Ther Adv Respir Dis 2012; 6(4): 211-9.

[66] Pascoal IF, Lindheimer MD, Nalbantian-Brandt C, Umans JG. Preeclampsia selectively impairs endothelium-dependent relaxation and leads to oscillatory activity in small omental arteries. J Clin Invest 1998; 101: 464-70.

[67] Cockell AP, Poston L. Flow-mediated vasodilatation is enhanced in normal pregnancy but reduced in preeclampsia. Hypertension 1997; 30: 247-51.

[68] McCarthy AL, Woolfson RG, Raju SK, Poston L. Abnormal endothelial cell function of resistance arteries from women with preeclampsia. Am J Obstet Gynecol 1993; 168: 1323-30.

[69] Chambers JC, Fusi L, Malik IS, Haskard DO, De Swiet M, Kooner JS. Association of maternal endothelial dysfunction with preeclampsia. JAMA 2001; 285: 1607-12.

[70] Poniedzialek-Czajkowska E, Marciniak B, Kimber-Trojnar Z, Leszczynska-Gorzelak B, Oleszczuk J. Nitric oxide in normal and preeclamptic pregnancy. Curr Pharm Biotechnol 2011; 12: 743-9.

[71] Edwards N, Blyton DM, Kirjavainen TT, Sullivan CE. Hemodynamic responses to obstructive respiratory events during sleep are augmented in women with preeclampsia. Am J Hypertens 2001; 14: 1090-5.

[72] Carlson JT, Rangemark C, Hedner JA. Attenuated endotheliumdependent vascular relaxation in patients with sleep apnoea. $\mathrm{J}$ Hypertens 1996; 14: 577-84.

[73] Kato M, Roberts-Thomson P, Phillips BG, et al. Impairment of endothelium-dependent vasodilation of resistance vessels in patients with obstructive sleep apnea. Circulation 2000; 102: 260710.

[74] Nieto FJ, Herrington DM, Redline S, Benjamin EJ, Robbins JA. Sleep apnea and markers of vascular endothelial function in a large community sample of older adults. Am J Respir Crit Care Med 2004; 169: 354-60.

[75] Ip MS, Lam B, Chan LY, et al. Circulating nitric oxide is suppressed in obstructive sleep apnea and is reversed by nasal continuous positive airway pressure. Am J Respir Crit Care Med 2000; 162: 2166-71.

[76] Schulz R, Schmidt D, Blum A, et al. Decreased plasma levels of nitric oxide derivatives in obstructive sleep apnoea: response to CPAP therapy. Thorax 2000; 55: 1046-51.

[77] Ohike Y, Kozaki K, Iijima K, et al. Amelioration of vascular endothelial dysfunction in obstructive sleep apnea syndrome by nasal continuous positive airway pressure--possible involvement of nitric oxide and asymmetric NG, NG-dimethylarginine. Circ J 2005; 69: 221-6.

[78] Ohga E, Nagase T, Tomita T, et al. Increased levels of circulating ICAM-1, VCAM-1, and L-selectin in obstructive sleep apnea syndrome. J Appl Physiol 1999; 87: 10-4.

[79] Dyugovskaya L, Lavie P, Lavie L. Increased adhesion molecules expression and production of reactive oxygen species in leukocytes of sleep apnea patients. Am J Respir Crit Care Med 2002; 165 : 934-9.

[80] Yinon D, Lowenstein L, Suraya S, et al. Pre-eclampsia is associated with sleep-disordered breathing and endothelial dysfunction. Eur Respir J 2006; 27: 328-33.

[81] Liao JK, Zulueta JJ, Yu FS, Peng HB, Cote CG, Hassoun PM. Regulation of bovine endothelial constitutive nitric oxide synthase by oxygen. J Clin Invest 1995; 96: 2661-6.

[82] McQuillan LP, Leung GK, Marsden PA, Kostyk SK, Kourembanas S. Hypoxia inhibits expression of eNOS via transcriptional and posttranscriptional mechanisms. Am J Physiol 1994; 267: H1921-7.

[83] Ayas NT, White DP, Manson JE, et al. A prospective study of sleep duration and coronary heart disease in women. Arch Intern Med 2003; 163: 205-9.

[84] Takase B, Akima T, Uehata A, Ohsuzu F, Kurita A. Effect of chronic stress and sleep deprivation on both flow-mediated dilation in the brachial artery and the intracellular magnesium level in humans. Clin Cardiol 2004; 27: 223-7.

[85] Jensen GM, Moore LG. The effect of high altitude and other risk factors on birthweight: independent or interactive effects? Am J Public Health 1997; 87: 1003-7.

[86] Miller S, Tudor C, Nyima, et al. Maternal and neonatal outcomes of hospital vaginal deliveries in Tibet. Int J Gynaecol Obstet 2007; 98: 217-21.
[87] Connolly G, Razak AR, Hayanga A, Russell A, McKenna P, McNicholas WT. Inspiratory flow limitation during sleep in preeclampsia: comparison with normal pregnant and nonpregnant women. Eur Respir J 2001; 18: 672-6.

[88] Guilleminault C, Palombini L, Poyares D, Takaoka S, Huynh NT, El-Sayed Y. Pre-eclampsia and nasal CPAP: Part 1. Early intervention with nasal CPAP in pregnant women with risk-factors for pre-eclampsia: preliminary findings. Sleep Med 2007; 9: 9-14.

[89] Poyares D, Guilleminault C, Hachul H, et al. Pre-eclampsia and nasal CPAP: Part 2. Hypertension during pregnancy, chronic snoring, and early nasal CPAP intervention. Sleep Med 2007; 9: 15-21.

[90] Narkiewicz K, Somers VK. Sympathetic nerve activity in obstructive sleep apnoea. Acta Physiol Scand 2003; 177: 385-90.

[91] Christou K, Moulas AN, Pastaka C, Gourgoulianis KI. Antioxidant capacity in obstructive sleep apnea patients. Sleep Med 2003; 4 : 225-8.

[92] Svatikova A, Wolk R, Lerman LO, et al. Oxidative stress in obstructive sleep apnoea. Eur Heart J 2005; 26: 2435-9.

[93] Koken G, Sahin FK, Cosar E, et al. Oxidative stress markers in pregnant women who snore and fetal outcome: a case control study. Acta Obstet Gynecol Scand 2007; 86: 1317-21.

[94] Okun ML, Coussons-Read ME. Sleep disruption during pregnancy: how does it influence serum cytokines? J Reprod Immunol 2007; 73: $158-65$.

[95] Okun ML, Hall M, Coussons-Read ME. Sleep disturbances increase interleukin-6 production during pregnancy: implications for pregnancy complications. Reprod Sci 2007; 14: 560-7.

[96] Teran E, Escudero C, Moya W, Flores M, Vallance P, LopezJaramillo P. Elevated C-reactive protein and pro-inflammatory cytokines in Andean women with pre-eclampsia. Int J Gynaecol Obstet 2001; 75: 243-9.

[97] Patel SR, Larkin EK, Mignot E, Lin L, Redline S. The association of angiotensin converting enzyme (ACE) polymorphisms with sleep apnea and hypertension. Sleep 2007; 30: 531-3.

[98] Koyama RG, Drager LF, Lorenzi-Filho G, et al. Reciprocal interactions of obstructive sleep apnea and hypertension associated with ACE I/D polymorphism in males. Sleep Med 2009; 10: 1107 11 .

[99] Lee P, Douglas NJ, Riha RL. The association of angiotensinconverting enzyme gene insertion/deletion polymorphisms with obstructive sleep apnoea: a meta-analysis. Eur Respir J 2011; 40(2): 394-9.

[100] Chen Z, Xu F, Wei Y, Liu F, Qi H. Angiotensin converting enzyme insertion/deletion polymorphism and risk of pregnancy hypertensive disorders: a meta-analysis. J Renin Angiotensin Aldosterone Syst 2012; 13: 184-95.

[101] Shaik AP, Sultana A, Bammidi VK, Sampathirao K, Jamil K. A meta-analysis of eNOS and ACE gene polymorphisms and risk of pre-eclampsia in women. J Obstet Gynaecol 2011; 31: 603-7.

[102] Bourjeily G, Barbara N, Larson L, He M. Clinical manifestations of obstructive sleep apnoea in pregnancy: More than snoring and witnessed apnoeas. J Obstet Gynaecol 2012; 32: 434-8.

[103] Centers for Disease Control and Prevention. National diabetes fact sheet: national estimates and general information on diabetes and prediabetes in the United States, 2011. Atlanta, GA: Department of Health and Human Services, Centers for Disease Control and Prevention, 2011.

[104] International Association of Diabetes and Pregnancy Study Groups Consensus Panel. International association of diabetes and pregnancy study groups recommendations on the diagnosis and classification of hyperglycemia in pregnancy. Diabetes Care 2010; 33: 676-82.

[105] Qiu C, Enquobahrie D, Frederick IO, Abetew D, Williams MA. Glucose intolerance and gestational diabetes risk in relation to sleep duration and snoring during pregnancy: a pilot study. BMC Womens Health 2010; 10: 17.

[106] Facco FL, Grobman WA, Kramer J, Ho KH, Zee PC. Self-reported short sleep duration and frequent snoring in pregnancy: impact on glucose metabolism. Am J Obstet Gynecol 2010; 203: 142.e1-5.

[107] Reutrakul S, Zaidi N, Wroblewski K, et al. Sleep disturbances and their relationship to glucose tolerance in pregnancy. Diabetes Care 2011; 34: 2454-7.

[108] Avogaro A, Toffolo G, Valerio A, Cobelli C. Epinephrine exerts opposite effects on peripheral glucose disposal and glucose- 
stimulated insulin secretion. A stable label intravenous glucose tolerance test minimal model study. Diabetes 1996; 45: 1373-8.

[109] Deibert DC, DeFronzo RA. Epinephrine-induced insulin resistance in man. J Clin Invest 1980; 65: 717-21.

[110] Lembo G, Capaldo B, Rendina V, et al. Acute noradrenergic activation induces insulin resistance in human skeletal muscle. Am J Physiol 1994; 266: E242-7.

[111] Martin IK, Weber KM, Boston RC, Alford FP, Best JD. Effects of epinephrine infusion on determinants of intravenous glucose tolerance in dogs. Am J Physiol 1988; 255: E668-73.

[112] Andrews RC, Walker BR. Glucocorticoids and insulin resistance: old hormones, new targets. Clin Sci 1999; 96: 513-23.

[113] Robertson RP, Harmon JS. Pancreatic islet beta-cell and oxidative stress: the importance of glutathione peroxidase. FEBS Lett 2007; 581:3743-8.

[114] Poyhonen-Alho M, Ebeling P, Saarinen A, Kaaja R. Decreased variation of inflammatory markers in gestational diabetes. Diabetes Metab Res Rev 2011; 27: 269-76.

[115] Wolf M, Sauk J, Shah A, et al. Inflammation and glucose intolerance: a prospective study of gestational diabetes mellitus. Diabetes Care 2004; 27: 21-7.

[116] Morisset AS, Dube MC, Cote JA, Robitaille J, Weisnagel SJ, Tchernof A. Circulating interleukin-6 concentrations during and after gestational diabetes mellitus. Acta Obstet Gynecol Scand 2011; 90: 524-30.

[117] Lain KY, Daftary AR, Ness RB, Roberts JM. First trimester adipocytokine concentrations and risk of developing gestational diabetes later in pregnancy. Clin Endocrinol (Oxf) 2008; 69: 40711 .
[118] Altinova AE, Toruner F, Bozkurt N, et al. Circulating concentrations of adiponectin and tumor necrosis factor-alpha in gestational diabetes mellitus. Gynecol Endocrinol 2007; 23: 161-5.

[119] Kirwan JP, Hauguel-De Mouzon S, Lepercq J, et al. TNF-alpha is a predictor of insulin resistance in human pregnancy. Diabetes 2002; 51: 2207-13.

[120] Lopez-Tinoco C, Roca M, Fernandez-Deudero A, et al. Cytokine profile, metabolic syndrome and cardiovascular disease risk in women with late-onset gestational diabetes mellitus. Cytokine 2012; 58: 14-9.

[121] Saucedo R, Zarate A, Basurto L, et al. Relationship between circulating adipokines and insulin resistance during pregnancy and postpartum in women with gestational diabetes. Arch Med Res 2011; 42: 318-23.

[122] McCormick MC. The contribution of low birth weight to infant mortality and childhood morbidity. N Engl J Med 1985; 312: 8290.

[123] Goldenberg RL, Culhane JF, Iams JD, Romero R. Epidemiology and causes of preterm birth. Lancet 2008; 371: 75-84.

[124] Hendler I, Goldenberg RL, Mercer BM, et al. The Preterm Prediction Study: association between maternal body mass index and spontaneous and indicated preterm birth. Am J Obstet Gynecol 2005; 192: 882-6.

[125] Micheli K, Komninos I, Bagkeris E, et al. Sleep patterns in late pregnancy and risk of preterm birth and fetal growth restriction. Epidemiology 2011; 22: 738-44.

[126] Lee KA, Gay CL. Sleep in late pregnancy predicts length of labor and type of delivery. Am J Obstet Gynecol 2004; 191: 2041-6.

[127] Evans ML, Dick MJ, Clark AS. Sleep during the week before labor: relationships to labor outcomes. Clin Nurs Res 1995; 4: 23849.

Received: March 07, 2012

Revised: November 08, 2012

Accepted: January 26, 2013

(C) Bourjeily et al.; Licensee Bentham Open.

This is an open access article licensed under the terms of the Creative Commons Attribution Non-Commercial License (http://creativecommons.org/licenses/by$\mathrm{nc} / 3.0 /$ ), which permits unrestricted, non-commercial use, distribution and reproduction in any medium, provided the work is properly cited. 